Raising Rivals' Costs in Complementary Goods Markets:

LECs Entering into Long Distance and Microsoft Bundling Internet Explorer

\author{
Nicholas Economides \\ Leonard N. Stern School of Business \\ New York University
}

March 1998

Working Paper Series

Stern \#IS-98-11 


\title{
Raising Rivals' Costs in Complementary Goods Markets: LECs Entering into Long Distance and Microsoft Bundling Internet Explorer ${ }^{*}$
}

\author{
by \\ Nicholas Economides ${ }^{* *}$
}

Revised March 19, 1998

\begin{abstract}
Frequently, a monopolist or dominant firm in an input market also sells a complementary product for which the input is indispensable. It is often the case that the monopolist faces significant competition in the complementary goods markets. For example, a LEC is a monopolist in the provision of terminating and originating access for long distance service. If it were presently allowed to offer long distance service, it would be competing with a number of other carriers. In a second important example, Microsoft is dominant in the operating systems market for personal computers and it also sells various applications that require the use of the operating system. In many of the applications markets, such as the market for internet browsers, Microsoft faces significant competition.

This paper shows that the monopolist has incentives (i) to raise the costs of its rivals in the complementary markets; and (ii) to degrade the quality of the monopolized good when this good is combined with complementary goods of its competitors. Such behavior is expected by LECs once they enter the long distance market. Microsoft may also have exhibited such behavior by (i) bundling Internet Explorer with Windows 95 ; and (ii) by seamlessly integrating Internet Explorer 4.0 with Windows Explorer in Windows 95 and Windows 98.
\end{abstract}

Key words: discrimination, raising rivals' costs, monopoly, vertical relations

JEL classification: $\mathrm{L} 1, \mathrm{D} 4$

* I thank Bob Kargoll and Steve Salop for helpful comments. Presented at the 1997 TPRC conference, October 1997. Forthcoming in the Annual Telecommunications Policy Research Conference 1997 Volume. Some of the results of this paper are based on "The Incentive for Non-Price Discrimination by an Input Monopolist," International Journal of Industrial Organization (1998). Many of the documents in the references can be found at http://raven.stern.nyu.edu/networks/ms/top.html.

** Stern School of Business, 44 W. 4th Street, New York, NY 10012. e-mail: neconomi@stern.nyu.edu. www: http://raven.stern.nyu.edu/networks/. Tel. (212) 998-0864. Fax (212) 995-42218. 


\section{Raising Rivals' Costs in Complementary Goods Markets: LECs Entering into Long Distance and Microsoft Bundling Internet Explorer}

\section{Introduction}

Suppose that a firm monopolizes a market that provides a required input for a complementary market. Assume further that the monopolist also provides the complementary product through a subsidiary. Besides the monopolist's subsidiary, a number of other independent companies participate in the complementary good market. Under these conditions, we show that the monopolist has an incentive to (i) raise the costs of the rivals to its downstream subsidiary; and (ii) degrade the quality of the monopolized good offered to the downstream rivals of its subsidiary. These actions of the monopolist reduce competition and social welfare.

The application of this model to telecommunications is immediate. Presently, a LEC has a monopoly over access origination and termination of all calls in the area over which it has a monopoly franchise. ${ }^{1}$ Access is a required input in the production of long distance calls. If a LEC is allowed in long distance, the setup matches the assumptions of the model. Thus, we expect, once a LEC is allowed in long distance, it will have the incentive to raise the costs of its long distance rivals as well as to degrade the quality of the access it sells to its long distance rivals. Given the anticompetitive effects that would result under these conditions, entry of LECs in long distance should not be allowed until there is vigorous competition in the local exchange market. We discuss the application to the telecommunications markets in more detail in section 3. 
This setup also has immediate applications to the Personal Computer ("PC") software market. The market for operating systems ("OS") is monopolized by Microsoft. Microsoft also produces software applications. In many of the application markets, Microsoft faces significant competition. Thus, the conditions of these markets fit the assumptions of the model. It follows that we expect that Microsoft has an incentive to raise the costs of its rivals in the applications arena and to degrade the quality of the operating system services that they receive compared to the quality of the operating system services that the Microsoft applications receive. We discuss the application of this model to the operating systems and internet browsers market in section 4 . This issue is particularly timely given the current case of the United States v. Microsoft.

\section{Theorems ${ }^{2}$}

This section proves the necessary mathematical results. Mathematics challenged readers can skip the proofs and proceed directly to the statements of the theorems.

Suppose that a firm is a monopolist in upstream market $\mathrm{A}$. The output of market $\mathrm{A}$ is required for production in market $\mathrm{B}$. Assume, for simplicity, that one unit of $\mathrm{A}$ is required for each unit of market B. The monopolist participates in the downstream market through a subsidiary which we name firm 1 . There are also $n-1$ independent firms competing in the downstream market $(\mathrm{i}=2, \ldots, \mathrm{n})$, making a total of $n$ competitors downstream. These firms produce a homogeneous product and choose their quantities strategically a-la-Cournot. 
Formally, let the monopolist have upstream (downstream) fixed cost $F^{U}\left(F^{D}\right)$, upstream constant marginal cost $c$, and sell all units at price $w$ realizing profits from upstream operations of

$$
\Pi_{1}^{U}=(w-c) Q-F^{U} .
$$

Downstream firm $i$ produces $q_{i}$ and total downstream production is $Q=q_{l}+\Sigma_{i \neq l} q_{i}$. Let downstream market price be $p(Q)$. Then the profits of the monopolist from the downstream market are

$$
\Pi_{1}^{\mathrm{D}}=(\mathrm{p}-\mathrm{s}-\mathrm{w}) \mathrm{q}_{1}-\mathrm{F}^{\mathrm{D}}
$$

with total profits of the monopolist being

$$
\Pi_{1} \equiv \Pi_{1}^{\mathrm{U}}+\Pi_{1}^{\mathrm{D}}=(\mathrm{w}-\mathrm{c}) \mathrm{Q}+(\mathrm{p}-\mathrm{s}-\mathrm{w}) \mathrm{q}_{1}-\left(\mathrm{F}^{\mathrm{U}}+\mathrm{F}^{\mathrm{D}}\right) .
$$

Downstream firms face an extra cost, denoted by $r$, that reflects the actions of the upstream monopolist to raise the costs of the rivals of its subsidiary through quality degradation and other actions. A typical independent firm $i$ has profits

$$
\Pi_{i} \equiv \Pi_{i}^{D}=(p-\underline{s}-w-r) q_{i}-F^{D} .
$$

Firms play a Cournot game that leads to equilibrium outputs $q_{r}^{*}, q_{i}^{*}, \mathrm{i}=2, \ldots, \mathrm{n}$, and $Q^{*}=q_{1}^{*}+(n-1) q_{i}^{*}$, with equilibrium price $\mathrm{p}\left(Q^{*}\right)$ and equilibrium profits $\Pi_{1}^{*}$ for the monopolist and $\Pi_{\mathrm{i}}^{*}$ for each independent firm. 
The crucial question is the variation of the monopolist's profits $\Pi_{1}^{*}$ with the level of the extra cost $r$ that it imposes on downstream rivals. If there exists a positive $r$ such that $\Pi_{1}^{*}(r)>\Pi_{1}^{*}(0)$, then the monopolist has an incentive to raise the costs by such $r>0$.

One way to search for such an $r$ is to examine the effect on the monopolist's equilibrium profits $\Pi_{1}^{*}$ of small increases of $r$ above zero. If we find $\mathrm{d} \Pi_{1}^{*} / \mathrm{dr}>0$, then the monopolist has an incentive to increase rivals' costs. Even if $\mathrm{d}_{1}^{*} / \mathrm{dr}<0$ at $r=0$, there _ still may exist some level of $r$ such that $\Pi_{1}^{*}(\mathrm{r})>\Pi_{1}^{*}(0)$ provided that for larger $r, \mathrm{~d} \Pi_{1}^{*} / \mathrm{dr}>$ 0 .

In this paper, we prove that, when the monopolist's subsidiary and the independent firms have the same costs, $\mathrm{d} \Pi_{1}^{*} / \mathrm{dr}>0$ for all $r>0$, and therefore the monopolist has an incentive to increase $r$ until the independent competitors are driven out of business (Theorem 1). In terms of social surplus, we show that increasing the downstream rivals' costs decreases social welfare (Theorem 2). When the monopolist's subsidiary has lower costs than the independents, the same is true (Theorem 3). When the monopolist's subsidiary has higher costs than the independents, we show that $\mathrm{d} \Pi_{1}^{*} / \mathrm{dr}<0$ for small $r$ and $\mathrm{d} \Pi_{1}^{*} / \mathrm{dr}>$ 0 for large $r$. In this case, we also show that the monopolist has an incentive to increase the costs of rivals until they are driven out of business (Theorem 3).

The key to all the theorems is the fact that all incentives are evaluated at the noncooperative (Cournot) equilibrium. When all firms use the same technology, this equilibrium is defined by

$$
\begin{gathered}
\mathrm{d} \Pi_{1} / \mathrm{dq}_{1}=\mathrm{p}+\mathrm{q}_{1} \mathrm{p}^{\prime}(\mathrm{Q})-(\mathrm{c}+\mathrm{s})=0 . \\
\mathrm{d} \Pi_{\mathrm{i}} / \mathrm{dq}_{\mathrm{i}}=\mathrm{p}+\mathrm{q}_{\mathrm{i}} \mathrm{p}^{\prime}(\mathrm{Q})-(\mathrm{w}+\mathrm{s}+\mathrm{r})=0 .
\end{gathered}
$$


for $i=2, \ldots, n$. Note that the monopolist has lower marginal costs of downstream output ( $c$ rather than $w$ ), since $w$ cancels out in its profits. This implies, that, even if the monopolist does not increase the costs of its downstream rivals $(r=0)$, the monopolist will be producing more downstream output than the independents.

Combining (5) and (6) by multiplying (6) with (n-1) and adding it to (5) we can define industry output $Q^{*}$ without reference to the individual firms' outputs:

$$
n p\left(Q^{*}\right)+Q^{*} p^{\prime}\left(Q^{*}\right)=n s+c+(n-1)(w+r) .
$$

To assess the effects of increases in rivals' costs $r$ on welfare and profits we need to calculate the effects on increases in $r$ on the output of independents, the monopolist's subsidiary and on total downstream output. The effect on industry output is easily derived from total differentiation of (7):

$$
\mathrm{dQ}^{*} / \mathrm{dr}=(\mathrm{n}-1) /\left[(\mathrm{n}+1) \mathrm{p}^{\prime}+\mathrm{Q}^{*} \mathrm{p}^{\prime \prime}\right] .
$$

This is negative when

$$
(\mathrm{n}+1) \mathrm{p}^{\prime}+\mathrm{Q}^{*} \mathrm{p}^{\prime \prime}<0
$$

Condition (9), a standard regularity condition in Cournot oligopoly, is equivalent to an equal increase in marginal cost of all firms resulting in a decrease in output and an increase in price, i.e.,

$$
\mathrm{dQ}^{*} / \mathrm{ds}<0 \Leftrightarrow \mathrm{dp}\left(\mathrm{Q}^{*}\right) / \mathrm{ds}>0 \Leftrightarrow(\mathrm{n}+1) \mathrm{p}^{\prime}+\mathrm{Q}^{*} \mathrm{p}^{\prime \prime}<0 \Leftrightarrow \mathrm{dQ} / \mathrm{dr}<0 .
$$

An increase in $r$ unambiguously reduces welfare since total industry sales are reduced.

Total differentiation of (5) implies 


$$
\mathrm{dq}_{1}^{*} / \mathrm{dr}=-\left(\mathrm{dQ}^{*} / \mathrm{dr}\right)\left(\mathrm{p}^{\prime}+\mathrm{q}_{1}^{*} \mathrm{p}^{\prime \prime}\right) / \mathrm{p}^{\prime}
$$

This is positive, given $d Q^{*} / d r<0$, when

$$
\mathrm{p}^{\prime}+\mathrm{q}_{1}^{*} \mathrm{p}^{\prime \prime}<0
$$

Condition (12) is also a standard regularity condition in Cournot oligopoly that is equivalent to a downward sloping best reply function of firm 1, or equivalently, that $\mathrm{q}_{1}$ and $\Sigma_{\mathrm{i} \neq 1} \mathrm{q}_{\mathrm{i}}$ are strategic substitutes.

We have shown that a discriminatory increase in the cost of downstream rivals results in a decrease in industry output, an increase in final output price, a decrease in the output of each independent firm, and an increase in the output of the monopolist's subsidiary.

The incentive that the upstream monopolist has to marginally increase the costs of the rivals of its downstream subsidiary is measured by

$$
\mathrm{d} \Pi_{1}^{*} / \mathrm{dr}=(\mathrm{w}-\mathrm{c})\left(\mathrm{dQ}^{*} / \mathrm{dr}\right)+\left(\mathrm{q}_{1}^{*} \mathrm{p}^{\prime}\right)\left(\mathrm{dQ}^{*} / \mathrm{dr}\right)+\left(\mathrm{p}^{-}-\mathrm{s}-\mathrm{w}\right)\left(\mathrm{dq}_{1}^{*} / \mathrm{dr}\right)
$$

The total effect of increases in $r$ on profits, $\mathrm{d} \Pi_{1}^{*} / \mathrm{dr}$, can be dissected (from (13)) in three parts. The first part, $(w-c)\left(\mathrm{dQ}^{*} / \mathrm{dr}\right)<0$, represents the reduction of profits of the monopolist in its upstream operations. The second part, $\left(\mathrm{q}_{1}^{*} \mathrm{p}^{\prime}\right)(\mathrm{dQ} / \mathrm{dr})>0$, represents the positive effect on the downstream subsidiary's revenues (holding the subsidiary's output constant) precipitated by the downstream price increase that results from increasing the costs of the independent competitors. The third part, $(\mathrm{p}-\mathrm{s}-\mathrm{w})\left(\mathrm{dq}_{\mathrm{i}}^{*} / \mathrm{dr}\right)>0$, represents the increased revenues from expanded sales of the subsidiary, keeping price constant. The essence of the 
proof that $\mathrm{d} \Pi_{1}^{*} / \mathrm{dr}>0$ relies on the fact that the combination of the first and the second parts is positive. Since the third part is positive (from the profit maximization condition of the independents), the result follows.

The proof flows easily from the profit maximization conditions of the firms. For each firm, marginal revenue must equal marginal cost so that

$$
M C_{i}-M C_{1}=M R_{i}-M R_{1} \Leftrightarrow w+r-c=\left(q_{i}^{*}-q_{1}^{*}\right) p^{\prime} .
$$

This implies

$$
w-c+q_{1}^{*} p^{\prime}=q_{i}^{*} p^{\prime}-r<0,
$$

It follows that the combination of the first two terms in (13) is positive,

$$
\left(w-c+q_{1}^{*} p^{\prime}\right)\left(d Q^{*} / d r\right)>0 .
$$

The third term in the marginal profit decomposition in (13) is also positive from is positive from the independents' profit maximization (6),

$$
\mathrm{p}-\mathrm{w}-\mathrm{s}=\mathrm{r}-\mathrm{q}_{\mathrm{p}} \mathrm{p}^{\prime}(\mathrm{Q})>0 \Rightarrow(\mathrm{p}-\mathrm{s}-\mathrm{w})\left(\mathrm{dq}_{1}^{*} / \mathrm{dr}\right)>0 \text {. }
$$

Combining the effects, we have that increases in rivals' costs result in increases in the profits of the monopolist. Further increases in rivals' costs result in even higher profits of the monopolist. Therefore the monopolist has an incentive to increase rivals' costs until they are driven out of business.

Theorem 1: A monopolist in an upstream market has an incentive to increase the costs of rivals to its downstream subsidiary until they are driven out of business. ${ }^{3}$ 


\section{Theorem 2: Any increase in rival's costs increases the subsidiary's output,}

decreases the output of rivals, decreases industry output, increases the downstream price, and decreases social welfare.

Our setup this far has been of a discriminatory strategy that increases the costs of downstream rivals but does not affect the demand functions of the subsidiary or of the independents. However, inspection of the profit maximization conditions (5) and (6) shows that our results also hold for a discriminatory degradation of the quality of the input offered to rivals which decreases the willingness to pay for the rivals' downstream output but leaves costs unaffected. In such a setup, independent downstream firms have marginal cost $w+s$, but, since they have a lower quality product, consumers are willing to pay only $p-r$ for their product (while consumers pay $p$ for the subsidiary's output). That is, the independents face a demand curve that is a parallel downward shift by $r$ of the demand faced by the subsidiary. In this setup, clearly the marginal profit of each firm is the same as before, and therefore the equilibrium quantities and profits are also the same. Thus, we have proved that our results hold if the strategy of raising rivals' cost is substituted by a discriminatory strategy of degrading the quality of the input supplied to the rivals so that the quality of the output of the rivals is degraded.

It can also be easily shown that the monopolist has no incentive to increase the costs of all downstream firms, including it subsidiary. Thus, the monopolist only has an incentive for increasing rivals costs in a discriminatory manner. 
We now examine the case of different production costs for the monopolist's subsidiary and the independents for linear demand. Suppose that the monopolist faces an extra marginal cost $x$ for downstream production. $x=0$ represents the standard case; $x>0(<0)$ if the monopolist has a cost disadvantage (advantage) in the downstream production. ${ }^{4}$ The monopolist's profits from downstream operations are now

$$
\Pi_{1}^{\mathrm{D}}=(\mathrm{p}-\mathrm{s}-\mathrm{w}-\mathrm{x}) \mathrm{q}_{1}-\mathrm{F}^{\mathrm{D}}
$$

while all other profit functions remain unaffected. For a linear demand

$$
\mathrm{p}=\mathrm{a}-\mathrm{bQ}
$$

with $a>w+s+r>0, b>0$, the Cournot equilibrium is now: ${ }^{5}$

$$
\begin{gathered}
\mathrm{q}_{\mathrm{i}}^{*}=[\mathrm{a-s}-\mathrm{cn}-\mathrm{nx}+(\mathrm{n}-1)(\mathrm{w}+\mathrm{r})] /[\mathrm{b}(\mathrm{n}+1)], \\
\mathrm{q}_{\mathrm{i}}^{*}=[\mathrm{a}+\mathrm{c}-\mathrm{s}+\mathrm{x}-2(\mathrm{w}+\mathrm{r})] /[\mathrm{b}(\mathrm{n}+1)], \quad \mathrm{i} \neq 1, \\
\mathrm{Q}^{*}=[(\mathrm{a}-\mathrm{s}) \mathrm{n}-\mathrm{c}-\mathrm{x}-(\mathrm{w}+\mathrm{r})(\mathrm{n}-1)] /[\mathrm{b}(\mathrm{n}+1)], \\
\mathrm{p}^{*} \equiv \mathrm{p}\left(\mathrm{Q}^{*}\right)=[\mathrm{a}+\mathrm{c}+\mathrm{ns}+\mathrm{x}+(\mathrm{n}-1)(\mathrm{w}+\mathrm{r})] /(\mathrm{n}+1),
\end{gathered}
$$

and the realized profits are:

$$
\begin{gathered}
\Pi_{1}^{\mathrm{U}^{*}}=(\mathrm{w}-\mathrm{c})[(\mathrm{a}-\mathrm{s}) \mathrm{n}-(\mathrm{w}+\mathrm{r})(\mathrm{n}-1)-\mathrm{c}-\mathrm{x}] /[\mathrm{b}(\mathrm{n}+1)]-\mathrm{F}^{\mathrm{U}}, \\
\Pi_{1}^{\mathrm{D}^{*}}=(\mathrm{a}+\mathrm{c}-\mathrm{s}+\mathrm{r}(\mathrm{n}-1)-2 \mathrm{w}-\mathrm{nx})(\mathrm{a}-\mathrm{s}-\mathrm{cn}-\mathrm{nx}+(\mathrm{w}+\mathrm{r})(\mathrm{n}-1)) /\left[\mathrm{b}(1+\mathrm{n})^{2}\right]-\mathrm{F}^{\mathrm{D}}, \\
\Pi_{\mathrm{i}}^{*}=(\mathrm{a}+\mathrm{c}-\mathrm{s}+\mathrm{x}-2(\mathrm{w}+\mathrm{r})]^{2} /\left[\mathrm{b}(\mathrm{n}+1)^{2}\right]-\mathrm{F}^{\mathrm{D}} .
\end{gathered}
$$

The incentive to marginally increase rivals' costs is measured by

$$
\mathrm{d} \Pi_{1}^{*} / \mathrm{dr}=\mathrm{d}\left(\Pi_{1}^{\mathrm{U}^{*}}+\Pi_{1}^{\mathrm{D}^{*}}\right) / \mathrm{dr}=2(\mathrm{n}-1)[\mathrm{a}+\mathrm{c}-\mathrm{s}+\mathrm{r}(\mathrm{n}-1)-2 \mathrm{w}-\mathrm{nx}] /\left[\mathrm{b}(\mathrm{n}+1)^{2}\right] .
$$


Positive production by independent firms implies

$$
\mathrm{q}_{\mathrm{i}}^{*}>0 \Leftrightarrow \mathrm{w}<(\mathrm{a}+\mathrm{c}+\mathrm{x}-\mathrm{s}-2 \mathrm{r}) / 2 .
$$

Therefore, substituting (27) in (28),

$$
\mathrm{d} \Pi_{1}^{*} / \mathrm{dr}>2(\mathrm{r}-\mathrm{x})(\mathrm{n}-1)(\mathrm{n}+1) /\left[\mathrm{b}(\mathrm{n}+1)^{2}\right] \equiv \mathrm{f}(\mathrm{r}) .
$$

Thus, when the monopolist has a cost advantage, $x<0$, or when the technologies are the same, $x=0$, the monopolist clearly has an incentive to raise rivals' costs by any feasible $r$, that is, $\mathrm{d} \Pi_{1}^{*} / \mathrm{dr}>0$ for all $r>0$. I next show that, when the monopolist has a cost disadvantage, $x>0$, he also has an incentive to significantly increase rivals' costs.

Considering $\Pi_{1}^{*}$ as a function of $r$, and integrating both sides of (29), results in

$$
\Pi_{1}^{*}(r)-\Pi_{1}^{*}(0)>\int_{0}^{r} f(r) d r
$$

Note that $\int_{0}^{2 x} f(r) d r=0$, and $f(r)>0$ for $r>x \geq 0$. Therefore, for any $r>2 x$,

$$
\Pi_{1}^{*}(\mathrm{r})-\Pi_{1}^{*}(0)>0+\int_{2 x}^{\mathrm{r}} \mathrm{f}(\mathrm{r}) \mathrm{dr}>0 .
$$

Thus, the monopolist has an incentive to raise rivals' costs by an amount that exceeds twice its own cost disadvantage. Also note that $\mathrm{d}^{2} \Pi_{1}^{*} / \mathrm{dr}^{2}>0$, so that the monopolist has an incentive to increase downstream rivals' costs to higher and higher levels, stopping only when the downstream rivals are out of business. This is an optimal policy from the point of view of the monopolist provided that at $r=2 x$ the sales of the independents from (24) are positive, i.e., when $a+c-s-2 w>x$. 
When the sales of the independents implied by (21) would be negative at $r=2 x$, the optimal policy for the monopolist is to set $r=(a+c-s+x-2 w) / 2$ or higher, so that all competitors are driven out of business, $\mathrm{q}_{i}^{*}=0$, and the monopolist remains the only active firm, realizing $\mathrm{q}_{1}^{*}=\mathrm{Q}^{*}, \mathrm{p}^{*}, \Pi_{1}^{\mathrm{U}^{*}}$, and $\Pi_{1}^{\mathrm{D}^{*}}$ from $(20),(22)-(25)$ at $n=1$. Thus, if the cost disadvantage of the monopolist's subsidiary is so large that $r=2 x$ would give negative sales to the independents, the monopolist will increase the rivals costs up to the point at which all independents are driven out of business.

\section{Theorem 3: Even if the monopolist's subsidiary has a cost advantage or} disadvantage compared to its rivals, the monopolist still has an incentive to increase the costs of rivals to its downstream subsidiary until they are driven out of business.

The above theorems point to strong incentives to discriminate against downstream rivals by raising their costs and drive them out of business. The traditional method of avoiding vertical foreclosure has been the imposition of imputation rules on the integrated monopolist. An imputation rule imposes a price floor for the output of the monopolist's subsidiary, equal to the upstream input price plus the cost of other inputs to a downstream firm. We show next that, when the monopolist raises the costs of its rivals, traditional imputation rules fail to safeguard against discrimination. Thus, imputation fails to safeguard even against foreclosure of downstream rivals. It follows that imputation also fails to safeguard against less extreme effects of discrimination. ${ }^{6}$ 
To survive, even if its fixed costs are zero, an independent firm has to have positive production,

$$
\mathrm{q}_{\mathrm{i}}^{*}>0 \Leftrightarrow \mathrm{a}+\mathrm{c}>2(\mathrm{w}+\mathrm{r})-\mathrm{x}+\mathrm{s}
$$

Substituting in equation (26) with $F^{D}=0$, independents' survival implies that the downstream market price should follow

$$
\mathrm{p}^{*} \geq \mathrm{w}+\mathrm{s}+\mathrm{r} \Leftrightarrow \mathrm{p}^{*}-(\mathrm{w}+\mathrm{s}) \geq \mathrm{r}
$$

i.e., that the downstream market price should exceed a floor equal to the sum of three costs:

(i) the monopolist's price of the upstream input to the rivals, $w$; (ii) the cost of other inputs to the downstream process, $s$; and, (iii) the cost to rivals that results from the monopolist's discrimination, $r$. It follows that the application of a traditional imputation floor of $p^{*} \geq w+$ $s$ is not sufficient. Firms can easily be foreclosed under the traditional imputation floor.

\section{Theorem 4: The monopolist can use the strategy of raising downstream rivals'} costs to circumvent traditional imputation floors and foreclose its rivals.

\section{Application to Telecommunications Markets}

In this section, we apply the results to telecommunications markets. The breakup of AT\&T by the Modification of Final Judgement ("MFJ") resulted in a potentially competitive long distance market and in a number of local monopolies for local services. In the 13 years that followed the MFJ, the long distance market has become effectively competitive. However, each local services market remained monopolized by a Local Exchange Carrier 
("LEC") which had an exclusive monopoly franchise in the period between the MFJ and the Telecommunications Act of 1996 ("Act" or "1996 Act").

The goal of the 1996 Act was to open all telecommunications markets to competition. To achieve this, the Act (i) envisions the elimination of artificial and regulatory barriers to entry; (ii) facilitates the entry of new competitors in local markets by creating two novel ways of entry; and (iii) allows for the entry of LECs in long distance markets only after they have fulfilled a number of conditions (including allowing entry in their respective local markets) and can prove that such entry is in the public interest.

By attempting to eliminate barriers to entry, the Act tries to structurally increase competition, especially in the local exchange market. The Act mandates interconnection by all carriers. To facilitate entry in the local exchange, the Act allows for two novel ways of entry besides entry through the installation of own facilities. The first way allows entry in the retailing part of the telecommunications business by requiring incumbent local exchange carriers ("ILECs") to sell at wholesale prices to entrants any retail service that they offer. ${ }^{8}$ Such entry is essentially limited to the retailing part of the market.

The second and most significant novel way of entry introduced by the Act is through leasing of unbundled network elements from incumbents. In particular, the Act requires that ILECs (i) unbundle their networks; and (ii) that they offer for lease to entrants network components (unbundled network elements, "UNEs") "at cost plus reasonable profit."9 Thus, the Act envisions the telecommunications network as a decentralized network of interconnected networks. 
Many firms, including the large interexchange carriers AT\&T and MCI attempted to enter the market through "arbitration" agreements with ILECs under the supervision of State Regulatory Commissions, according to the procedure outlined by the Act. The arbitration process proved to be extremely long and difficult, with continuous legal obstacles and appeals raised by the ILECs. To this date (January 1998); almost two years after the signing of the Act by President Clinton, arbitrations have been concluded in very few States, and entry in the local exchange has been minimal.

The 1996 Act establishes three general requirements that Bell Operating Companies ("BOCs") must fulfill before being permitted to provide in-region interLATA services. First, the $\mathrm{BOC}$ must show that it is providing interconnection to other local exchange providers that provide services predominantly over their own facilities. Moreover, the terms and conditions under which the BOC provides such interconnection to competitive carriers must conform to and fully implement the standards established by section 271 of the 1996 Act.

Second, a BOC seeking to provide in-region interLATA services must comply with the 1996 Act's non-discrimination and structural separation provisions. The FCC has interpreted these provisions to mean that not only must the BOC not discriminate among third parties, but that regulators must also be able to establish that the $\mathrm{BOC}$ does not discriminate between itself (or subsidiaries) and third party providers.

Finally, the 1996 Act requires that the FCC determine whether the approval of a BOC application to provide in-region interLATA service in a particular state is in the public interest. From an economic standpoint, such a determination requires an assessment that shows that the benefits accruing to telecommunications consumers because of approval of the 
application exceed any and all potential harm to those consumers resulting from BOC entry into long distance.

The Act allows entry of local companies in long distance after a checklist of conditions have been met. ${ }^{10}$ The 1996 Act provides that even if all these conditions are met, the entry of RBOCs into long distance must also be in the public interest. This implies that there is a significant hurdle for RBOCs' entry in long distance which may be more difficult to overcome than the fulfillment of the above checklist.

Despite significant efforts by entrants, primarily inter-exchange carriers ("IXCs"), to enter local exchange markets by leasing unbundled network elements from incumbents, the-

incumbents have found a variety of ways to circumvent such entry. ${ }^{11}$ Thus, if regulators presently allow entry of a local exchange carrier in the long distance market in the LEC's own region, such a LEC will be a monopolist in access. Since access is a required input for long distance service, a vertically integrated LEC providing in-region long distance would closely fit the assumptions of our model. ${ }^{12}$ Thus, the LEC will have an incentive to raise the costs of the downstream rivals of its long distance subsidiary and skirt imputation rules set by regulators. Such actions are anti-competitive and against the public interest. Because there is no discernable benefit of entry of LECs into long distance (since the long distance market is already effectively competitive), entry of LECs into in-region long distance service is not in the public interest and should not be allowed until there is vigorous competition in the local exchange market.

\section{Application to the Operating Systems-Browsers Markets}


The market for operating systems for personal computers is monopolized by Microsoft. $^{13}$ In 1994, the US Department of Justice sued Microsoft for monopolization and other offenses. The case was settled by a consent decree in $1995 .{ }^{14}$ On October 20,1997 , the Department of Justice asked the court supervising the implementation of the 1994 consent decree to find Microsoft in civil contempt and to fine Microsoft $\$ 1$ million per day for allegedly violating the licensing part of the consent decree.

Among others, the DOJ alleges that Microsoft violated section IV(E) of the consent decree. Section IV(E) of the consent decree states under "prohibited conduct:"

"E. Microsoft shall not enter into any License Agreement [with an OEM] in which the terms of that agreement are expressly or impliedly conditioned upon: (i) the licensing of any other Covered Product, Operating System Software product or other product (provided, however, that this provision in and of itself shall not be construed to prohibit Microsoft from developing integrated products); or (ii) the OEM not licensing, purchasing, using or distributing any non-Microsoft product."

The DOJ alleges that Microsoft required Original Equipment Manufacturers ("OEMs") to install Internet Explorer 3 ("IE3.0") and Internet Explorer 4 ("IE4.0") if they installed Windows 95 on new personal computers, and that this violated section IV(E) of the consent decree.

Judge Jackson issued a preliminary injunction on December 11, 1997 requiring Microsoft to provide an "unbundled choice" of Windows 95 by itself to OEMs. ${ }^{15}$ Microsoft complied on January $22,1998 .^{16}$ Up that time, Microsoft claimed that it was technically unfeasible to unbundle Internet Explorer from Windows 95 without damaging the functionality 
of Windows95. This is an important issue of fact that needs to be clarified. Another important issue in the case is if the Internet Explorer is a "product" with its own market, as DOJ claims, rather than another "feature" or "function" of Windows 95 as Microsoft claims. This is particularly important since the consent decree (see the quote from the Consent Decree above) allows Microsoft to create "integrated products."

Besides these important issues of fact which we will not discuss in this paper, there is the crucial issue: wass the alleged Microsoft behavior (which Microsoft has not disputed this far) anticompetitive?

The results of this paper show that Microsoft has an incentive to impose on OEMs the requirement that they also install Internet Explorer so that rivals' costs are raised. In the context of the framework of this paper, the alleged actions of Microsoft appear to be increasing rivals' costs and therefore be anticompetitive. If it takes time or effort for a user to install a competing browser, Microsoft has an advantage if its browser is already installed by the PC manufacturer. This advantage can be significant if Microsoft bundles IE3.0 and IE4.0 and Windows95, given the very large market share of Windows 95 in the market for operating systems for PCs.

Moreover, the seamlessly integrated IE4.0 in Windows Explorer in late versions of Windows 95 (and very likely in Windows 98 ) provides an integrated product that many may find superior to the combination of disintegrated Windows 95 (and Windows98) and an internet browser. Presently, the hooks that integrate IE4.0 with Windows Explorer are only known to Microsoft. Thus, Microsoft effectively sells an operating system which is of lower quality when used with an "outside" browser. Therefore any competitor in the browser market is 
disadvantaged, since it cannot create a product of equal features. This paper has shown that the degradation of quality of the monopolized product when this product is combined with complementary products of competitors is anticompetitive and harmful to social welfare.

A level playing field will be restored and the public interest will be protected if Microsoft discloses the hooks that integrate IE4.0 with Windows Explorer so rival browsers to be equally seamlessly integrated with the operating system and are not disadvantaged. This is not the present remedy asked by DOJ, but it may be one that will be proposed in the investigation of Windows 98 that, according to Reuters, the DOJ is currently pursuing.

It should be noted that Microsoft's ability to raise rivals' costs is limited by the fact that Microsoft has traditionally opted for open systems and discloses APIs that allow independent software developers to create applications that run on Windows operating systems. It has been claimed that Microsoft's monopoly power (and associated ability to raise rivals costs) arises from its control of the "desktop" of a PC, i.e., the appearance of the PC's screen, and of Windows Explorer, a program that manages various key tasks. However, it is feasible for an independent software developer to replace the whole desktop without replacing the operating system. In fact, as early as 1995 , Symantec has been selling a replacement for Windows Explorer. Thus, the extent to which browser rivals' costs can be raised is limited by the availability of very close substitutes for the "desktop" and Windows Explorer sold by independent vendors. This limits the extent of welfare loss that can be created by raising rivals' costs and, in imposing remedies, should be balanced with possible adverse effects of the remedies. Potential adverse effects of the disclosure remedy are a lack 
of control of the Windows code, a potential dilution of the trademark of Windows, and a slowing of technological change.

\section{Concluding Remarks}

This paper examines an industry where a monopolist produces an input that is required for the production of complementary goods or services, and the monopolist has a subsidiary that produces the complementary good or service. This setup of this paper would describe telecommunications markets if incumbent local exchange carriers entered the long distance market (as they have-frequently asked) before vigorous competition emerges in the local exchange market. This setup also describes the state of competition in personal computers where Microsoft has a monopoly in operating systems and also produces applications (complementary goods) such as Internet browsers.

We prove that a monopolist has strong incentives to raise the costs of the rivals to its subsidiary until they are driven out of business, and that such actions are anti-competitive and detrimental to social welfare. In the telecommunications application, the results of this paper predict that once local exchange carriers enter long distance they will have incentives to disadvantage competitors by raising their costs or degrading their quality. ${ }^{17}$ In the computer application, the model predicts that Microsoft will increase the costs of its applications rivals as well as degrade the quality of the Operating System it monopolizes when used with applications of competitors. The DOJ, in its 1994 case against Microsoft, had alleged the existence of "hidden functions" in Windows95 that gave an anti-competitive advantage to Microsoft. As explained in detail in section 4 of this paper, bundling of Internet Explorer 
with Windows 95 , which is at the center of the current DOJ case against Microsoft, may raise rivals' costs.

Moreover the seamless integration of Internet Explorer 4.0 with Windows Explorer in Windows 95 (and very likely in Windows 98 ) effectively lowers the quality of the operating system when used with an unintegrated browser. Presently, competing browsers do not have access to the hooks that would allow the seamless integration of their browsers to the operating system. A remedy that would level the playing field would be the public disclosure of the hooks that make the seamless integration possible. However, because of the existence of competing "desktop" and "file manager" applications, the ability of Microsoft to raise browser rivals' costs is limited and can be overcome if competitors offer browsers that are sufficiently superior to Internet Explorer. In contrast, facing no close substitutes to its access monopoly, a local telephone company with a long distance subsidiary has unlimited ability to raise the costs of long distance competitors. 


\section{References}

Beard, T. Randolph, David I. Kaserman, John W. Mayo, "Regulation, Vertical Integration, and Sabotage," mimeo. (November 1996).

Bernheim Douglas, and Robert Willig, (1996), "The Scope of Competition in Telecommunications," AEI Studies in Telecommunications Deregulation, Working Paper; October 25, 1996.

Economides, Nicholas, (1996), "The Economics of Networks," International Journal of Industrial Organization, vol. 14, no. 6, pp. 675-699.

Economides, Nicholas, (1998a), "The Incentive for Non-Price Discrimination by an Input Monopolist" forthcoming, International Journal of Industrial Organization.

Economides, Nicholas, (1998b), "Quality Choice and Vertical Integration," forthcoming International Journal of Industrial Organization.

Economides, Nicholas and William Lehr (1995), "The Quality of Complex Systems and Industry Structure," Quality and Reliability of Telecommunications Infrastructure, W. Lehr (ed.). Lawrence Erlbaum. Hillsdale: 1995. 
Krattenmaker, Thomas, and Salop, Steven, C., (1986), "Anti-competitive Exclusion: Raising Rival's Costs to Achieve Power over Price," Yale Law Journal, vol. 96, pp. 209-293.

Microsoft Corp. (1998), "Competition in the Software Industry," http://microsoft.com/corpinfo/doj/1-98whitepaper.htm.

Salop, Steven C. and David Scheffman, (1983), "Raising Rival's Costs," American EconomicReview, vol. 73, pp. 267-271.

Sibley, David, and Dennis Weisman, (1995), "Competitive Incentives of Vertically Integrated Local Exchange Carriers," mimeo.

United States Department of Justice, (1997), "Petition by the United States for an Order to Show Cause Why Respondent Microsoft Corporation Should not be Found in Civil Contempt," filed October 20, 1997.

United States v. Microsoft Corporation, (1995), "Final Judgement," Civil Action No. 94-1564 (1994), filed August 21, 1995.

United States v. Microsoft Corporation, (1997a), "Memorandum and Order," Civil Action 941564 (TPJ), filed December 11, 1997. 
United States v. Microsoft Corporation, (1997b), "Order of Reference to Special Master," Civil Action 94-1564 (TDJ), filed December 11, 1997.

United States v. Microsoft Corporation, (1998), "Stipulation and Order," Supplemental to Civil Action No. 94-1564. 
1. Competitive Local Exchange Carriers (CLECs) have less than 1\% market share in access origination and termination.

2. This section is based on Economides (1998a).

3. The derivation shows that condition (9) (decrease in industry output as a response to a marginal cost increase) is sufficient for the result.

4. A cost advantage for the monopolist may arise when there are synergies in the joint production of the upstream and downstream components.

5. In comparison to the case of no extra cost to the monopolist $(x=0)$, in the equilibrium with $x>0$, production by independents and market price are higher, while production by the integrated monopolist and industry-wide production are lower.

6. Even in the absence of non-price discrimination strategies, such as the strategy of raising rivals costs, imputation cannot fully safeguard against price discrimination effects. Even if the integrated monopolist adheres to an imputation rule and charges itself as much as it charges others for the essential input, in the profit maximization of the integrated firm, the cost of using one more unit of this input is its true marginal cost, and not what the integrated firm charges others (and itself). Thus, since the integrated firm makes more profit for every unit of output than its rivals even when, under Cournot, they all sell at the same downstream price, the integrated firm in equilibrium has a higher scale of operation and can, for some range of fixed costs, foreclose its opponents.

Moreover, for an imputation policy to have the desired effect, full observability of costs is required -- a condition that is unlikely to be fulfilled. This may be particularly difficult since typically firms do not have an incentive to accurately reveal their costs to the regulator.

7. The LECs are the 7 original Regional Bell Operating Companies ("RBOCs") that came out of the breakup of AT\&T (Ameritech, Bell Atlantic, BellSouth, NYNEX, Pacific Bell, Southwestern Bell, US West), plus a number of independents, the largest of which is GTE. In 1996, Southwestern Bell (SBC) acquired Pacific Bell, and, in 1997, Bell Atlantic Acquired NYNEX, thus reducing the number of RBOCs to 5. In December 1997, SBC announced its intention to acquire SNET.

8. ILECs are required to set wholesale rates at their retail price minus "avoided costs." Such costs include various retailing and marketing costs.

9. The FCC and State Regulatory Commissions interpreted "at cost plus reasonable profit" to mean Total Element Long Run Incremental Cost ("TELRIC") which is the forward looking, long run, (minimized) economic cost of an unbundled element and includes the competitive return on capital. 
10. The checklist consists of:

(i) Interconnection in accordance with the requirements of sections 251(c)(2) and 252(d)(1).

(ii) Nondiscriminatory access to network elements in accordance with the requirements of sections $251(\mathrm{c})(3)$ and 252(d)(1).

(iii) Nondiscriminatory access to the poles, ducts, conduits, and rights-of-way (...) at just and reasonable rates (...).

(iv) Local loop transmission from the central office to the customer's premises, unbundled from local switching or other services.

(v) Local transport from the trunk side of a wireline local exchange carrier switch unbundled from switching or other services.

(vi) Local switching unbundled from transport, local loop transmission, or other services.

(vii) Nondiscriminatory access to

(I) 911 and E911 services;

(II) directory assistance services to allow the other carrier's customers to obtain telephone numbers; and

(III) operator call completion services. White pages directory listings for customers of the other carrier's telephone exchange service.

(ix) Until the date by which telecommunications numbering administration guidelines, plan, or rules are established, nondiscriminatory access to telephone numbers for assignment to the other carrier's telephone exchange service customers. After that date, compliance with such guidelines, plan, or rules.

(x) Nondiscriminatory access to databases and associated signaling necessary for call routing and completion.

(xi) Until the date by which the Commission issues regulations pursuant to section 251 to require number portability, interim telecommunications number portability through remote call forwarding, direct inward dialing trunks, or other comparable arrangements, with as little impairment of functioning, quality, reliability, and convenience as possible. After that date, full compliance with such regulations.

(xii) Nondiscriminatory access to such services or information as are necessary to allow the requesting carrier to implement local dialing parity in accordance with the requirements of section 251(b)(3).

(xiii) Reciprocal compensation arrangements in accordance with the requirements of section 252(d)(2).

(xiv) Telecommunications services are available for resale in accordance with the requirements of sections $251(\mathrm{c})(4)$ and $252(\mathrm{~d})(3)$.

11. ILECs also control wholesale services and UNEs, which are vital inputs for providing local services. Thus, in the absence of regulation, ILECs are able to control access and entry in the local exchange market.

12. An ILEC entrant in long distance can easily resell long distance service of interexchange carriers, as SNET does in Connecticut by reselling Sprint's long distance service, and as BellSouth does in out-of-region long distance by reselling AT\&T's long distance service. Thus, 
even in the short run, an ILEC entry in long distance is not expected to face significantly higher costs than IXCs in providing long distance service.

13. However, Microsoft has been selling its operating system at a relatively low price. This may be a consequence of the fact the operating systems are durable. Under some circumstances, a durable goods monopolist is forced to sell at prices that are very close to marginal cost. These tendencies may be accentuated in the presence of network externalities. Alternatively, the low OS price may reflect Microsoft's perception of the existence of significant potential competition in the market for operating systems. See Microsoft (1998).

14. See United States v. Microsoft Corporation (1995). A significant amount of controversy arose because Judge Sporkin, the supervising judge, would not approve the consent decree. The consent decree was finally signed by Judge Thomas Penfield Jackson.

15. See United States v. Microsoft Corporation, (1997a). On December 11, 1997, Judge Jackson also appointed Professor Lawrence Lessig as a "special master" to advise him on "the complex issues of cybertechnology and contract interpretation connected therewith." See United States v. Microsoft Corporation, (1997b). Subsequently Microsoft objected to both the use of a special master in principle, as well as to Prof. Lessig himself alleging bias. However, both objections were dismissed by the judge in subsequent hearings. Nevertheless, on appeal by Microsoft, the Court of Appeals set the Special Master aside, at least temporarily, on the grounds that his service may not be necessary.

16. See United States v. Microsoft Corporation, (1998).

17. Such behavior has been observed in New Zealand which has weaker regulatory supervision and relatively liberal competition laws. The incumbent monopolist, Telecom New Zealand, was able to repeatedly thwart efforts of entrants to offer innovative products by using various delaying tactics and lowering the quality of network services. Bernheim and Willig (1996) document various cases of raising costs of rivals in the United States. 